\title{
Clinical Implications of the 2013 ESH/ESC Hypertension Guidelines: Targets, Choice of Therapy, and Blood Pressure Monitoring
}

\author{
Sverre E. Kjeldsen • Tonje A. Aksnes • Luis M. Ruilope
}

Published online: 20 May 2014

(C) The Author(s) 2014. This article is published with open access at Springerlink.com

\begin{abstract}
The European Society of Hypertension (ESH)/ European Society of Cardiology (ESC) 2013 guidelines for the management of arterial hypertension included simplified blood pressure (BP) targets across patient groups, more balanced discussion on monotherapy vs. combination therapy, as well as reconfirmation of the importance of outof-office BP measurements. In light of these updates, we wished to review some issues raised and take a fresh look at the role of calcium channel blocker (CCB) therapy; an established antihypertensive class that appears to be a favorable choice in many patients. Relaxed BP targets for
\end{abstract}

S. E. Kjeldsen $(\bowtie)$

Department of Cardiology,

Oslo University Hospital, Ullevål, Oslo, Norway

e-mail: sverrkj@online.no; s.e.kjeldsen@medisin.uio.no

T. A. Aksnes

Department of Cardiology,

Akershus University Hospital,

Lørenskog, Norway

L. M. Ruilope

Hypertension Unit,

Hospital 12 de Octubre,

Madrid, Spain high-risk hypertensive patients in the 2013 ESH/ESC guidelines were driven by a lack of commanding evidence for an aggressive approach. However, substantial evidence demonstrates cardiovascular benefits from more intensive BP lowering across patient groups. Individualized treatment of high-risk patients may be prudent until more solid evidence is available. Individual patient profiles and preferences and evidence for preferential therapy benefits should be considered when deciding upon the optimal antihypertensive regimen. CCBs appear to be a positive choice for monotherapy, and in combination with other agent classes, and may provide specific benefits beyond BP lowering. Ambulatory and home BP monitoring have an increasing role in defining the diagnosis and prognosis of hypertension (especially non-sustained); however, their value for comprehensive diagnosis and appropriate treatment selection should be more widely acknowledged. In conclusion, further evidence may be required on BP targets in high-risk patients, and optimal treatment selection based upon individual patient profiles and comprehensive diagnosis using out-of-office BP measurements may improve patient management. 


\section{Key Points}

While a lack of compelling evidence for aggressive blood pressure (BP) targets in high-risk patients with hypertension has driven more relaxed target recommendations in the European Society of Hypertension/European Society of Cardiology 2013 guidelines for the management of arterial hypertension, substantial evidence exists that further cardiovascular (CV) benefits are available from more intensive BP lowering. Until more solid evidence is available, individualized treatment of high-risk patients may be prudent

Selection of the optimal therapy regimen should be based on a patient's individual demographics, BP, $\mathrm{CV}$ risk, co-morbidities, and preference, as well as evidence for preferential beyond-BP-lowering benefits of different antihypertensive agents. Calcium channel blockers are a favorable choice for monotherapy and in combination with other agent classes in many patients, and may provide benefits over other classes for certain CV outcomes

Out-of-office BP measurements provide more comprehensive information to inform accurate diagnoses of hypertensive conditions, and are more prognostic of patient outcome than office measurements. Ambulatory and home BP monitoring are likely to play an increasing role in hypertension management in the future, although their value for patient evaluation and appropriate treatment selection should be more widely acknowledged

\section{Introduction}

The European Society of Hypertension (ESH) and the European Society of Cardiology (ESC) guidelines for the management of arterial hypertension were updated in 2013, implementing a number of changes since the previous 2007 version [1, 2]. A key amendment for 2013 was the recommendation for more simplified blood pressure (BP) targets across groups of patients with hypertension, with all subjects to be treated to systolic BP (SBP) of $<140 \mathrm{mmHg}$ (apart from elderly patients) and to diastolic BP (DBP) of $<90 \mathrm{mmHg}$ (apart from those with diabetes mellitus) [2]. Further updates in the ESH/ESC guidelines include: more specific lifestyle recommendations, such as limiting salt intake to 5-6 g/day and lowering body mass index to $25 \mathrm{~kg} / \mathrm{m}^{2}$; more balanced discussion on the advantages and disadvantages of initiating monotherapy versus combination therapy; recommendation against dual renin-angiotensin system (RAS) blockade (owing to concerns about renal damage and increased incidence of stroke); reconfirmation of the importance of ambulatory BP monitoring (ABPM) and strengthened endorsement of the prognostic value of home BP monitoring (HBPM) for the diagnosis of isolated office ('white coat') and isolated ambulatory ('masked') hypertension [2].

With regard to the choice of antihypertensive agent, the 2013 ESH/ESC guidelines reconfirm that a diuretic, $\beta$ blocker, calcium channel blocker (CCB), angiotensin II receptor blocker (ARB), and angiotensin-converting enzyme (ACE) inhibitor are all suitable for use as monotherapy, and in some combinations with each other [2]. Of these agents, $\beta$-blockers appear to be losing favor as recommended initial monotherapy in other recent guidelines [3, 4], and the combination of an ARB and an ACE inhibitor is no longer endorsed [2-4]. Dihydropyridine CCBs have no compelling contraindications for use and are a preferred drug in many combination strategies [2], making them a favorable choice for many hypertensive patients. Indeed, CCBs have been cleared of the suspicion of increasing the incidence of coronary events $[2,5]$; and these agents may even be slightly more effective than other agents in preventing stroke [6-8]. In the light of the ESH/ ESC guidelines update, we wished to take a fresh look at this established class of antihypertensive agent.

The aim of this article is to review some key issues raised in the updated $2013 \mathrm{ESH} / \mathrm{ESC}$ guidelines, with a particular focus on the role of CCB therapy.

\section{Simplified BP Targets vs. the 'Lower the Better'}

The achieved level of SBP and DBP control is directly associated with the risk of cardiovascular (CV) disease (CVD) and stroke, across patient ages and ethnicities [9, 10]. Reducing the incidence of mortality and morbidity associated with CVD is linked to substantial socioeconomic and healthcare cost savings [11]. Therefore, should BP targets be more aggressive than suggested in the latest 2013 ESH/ESC guidelines?

The $2013 \mathrm{ESH} / \mathrm{ESC}$ recommendation for a BP target of $<140 / 90 \mathrm{mmHg}$ for most patients is based on a review of randomized controlled trial (RCT) data [12] that suggested a lack of evidence for a more aggressive, and previously recommended, BP target of $<130 / 80 \mathrm{mmHg}$ in patients with high CV risk [2]. However, the authors of the review state that despite scant evidence for lowering SBP below $130 \mathrm{mmHg}$ in patients with diabetes or high/very high CV risk, a more aggressive approach may be prudent because antihypertensive therapy to lower SBP to $<130 \mathrm{mmHg}$ 
appears well tolerated; they suggest more solid trial evidence should be gained [12].

Despite many major trials not achieving BP targets of $<140 / 90 \mathrm{mmHg}$, there is a wealth of evidence to indicate a relationship between lower $\mathrm{BP}$ and reduced $\mathrm{CV}$ outcomes, suggesting further benefits are available from greater BP reductions. Certainly, in low-to-moderate risk patients with uncomplicated hypertension, trial evidence supports that a reduction in SBP to $<140$ vs. $>140 \mathrm{mmHg}$ is associated with reduced adverse CV outcomes [13-15]. Other supportive evidence for intensive BP lowering in a range of patients is available, showing a lower risk of major CV events, especially stroke $[16,17]$ (Table 1). Law et al. performed a meta-analysis of data from randomized trials of BP-lowering therapy involving almost half a million patients (with and without CVD), and observed substantial reductions in heart disease and stroke for a $10-\mathrm{mmHg}$ reduction in SBP or a 5-mmHg reduction in DBP, down to $110 / 70 \mathrm{mmHg}$ [6]. A further meta-analysis of 32 randomized trials showed that reduction of SBP to 126 vs. $131 \mathrm{mmHg}$ had the same proportional $\mathrm{CV}$ benefits as a reduction to 140 vs. $145 \mathrm{mmHg}$ [18]. The Heart Outcomes Prevention Evaluation (HOPE) study demonstrated significant reductions in the risk of a composite outcome of $\mathrm{CV}$ mortality, myocardial infarction (MI), and stroke following antihypertensive treatment down to a SBP of $134 \mathrm{mmHg}$ [19]. Additionally, the Perindopril pROtection aGainst REcurrent Stroke Study (PROGRESS) trial (in patients with a history of stroke) revealed that the lowest follow-up BP levels (median 112/72 $\mathrm{mmHg}$ ) were associated with the lowest risk of stroke recurrence, with progressively increased risk at higher BP levels [20]. The Hypertension Optimal Treatment (HOT) study revealed the benefits of intensive lowering of DBP, with a mean DBP of $82.6 \mathrm{mmHg}$ being associated with the lowest incidence of major CV events and $86.5 \mathrm{mmHg}$ with the lowest risk of CV mortality [21]. In patients with diabetes, a DBP target of $\leq 80 \mathrm{mmHg}$ was associated with a $51 \%$ reduction in major CV events compared with a DBP target of $\leq 90 \mathrm{mmHg}(p=0.005)$ [21]. Conversely, in the Action to Control Cardiovascular Risk in Diabetes (ACCORD) study, the authors concluded that intensive BP lowering (to SBP $<120 \mathrm{mmHg}$ ) in patients with diabetes failed to reduce the risk of a composite outcome of fatal and nonfatal CV events, compared with standard BP reduction (to SBP $<140 \mathrm{mmHg}$ ) [22]. However, ACCORD was underpowered, because the event rate in the standard treatment arm was around half of that expected; this was reflected in a wide confidence interval for the primary outcome hazard ratio (HR) estimate that pointed to a potential $27 \%$ benefit in favor of intensive treatment (event rate was $2.09 \% / y e a r$ for standard therapy and $1.87 \%$ /year in the intensive arm). Furthermore, ACCORD demonstrated significant improvements in the pre-specified secondary endpoint of rate of stroke (total and non-fatal) with intensive treatment (for any stroke: standard therapy, $0.53 \% / y e a r ;$ intensive therapy, $0.32 \% / y e a r ; p=0.01$ ) and HR curves for the primary outcome, stroke, and MI showed separation at 5-8 years, suggesting longer-term $\mathrm{CV}$ benefits of tight $\mathrm{BP}$ control. Nonetheless, it should be noted that patients in the intensive treatment arm of ACCORD demonstrated more serious treatment-related adverse events (AEs) (including hypotension, arrhythmia, and hyperkalemia) and reduced renal function (estimated glomerular filtration rate) [22]. A meta-analysis of 15 trials of intensive BP lowering demonstrated risk reductions of 11-13\% for major CV events, MI, and end-stage kidney disease and of $24 \%$ for stroke, but with no clear effect on mortality [16] (Fig. 1). Intensive $\mathrm{BP}$ reduction did not increase the rate of drug discontinuation or the incidence of serious AEs, apart from hypotension, which occurred infrequently $(0.4 \% / 100$ personyears) [16].

\subsection{Would High-Risk Patients Benefit from More Intensive Treatment?}

While $<140 / 90 \mathrm{mmHg}$ appears to be an agreed target for low-risk hypertensive patients, there is still a lack of consensus among different international guidelines on BP targets for high-risk patients (Table 2, [2-4, 23-25]). The recommendation for less aggressive BP targets in high-risk individuals appears to be a common feature of the more recent guideline updates [2-4]. Nevertheless, the Canadian 2013 recommendations retained a target $\mathrm{BP}$ of $<130 /$ $80 \mathrm{mmHg}$ for patients with diabetes [23].

For patients with diabetes, the only trials to achieve a SBP reduction to $<130 \mathrm{mmHg}$ were the normotensive subgroup of the Appropriate Blood Pressure Control in Diabetes (ABCD) trial and the ACCORD trial [22, 26]. Both of these trials failed to show the benefit of intensive BP lowering on their primary outcome (change in creatinine clearance and fatal and non-fatal CV events, respectively); however, the positive outcomes from ACCORD are described above, and $A B C D$ demonstrated that intensive BP lowering (mean BP of 128/75 vs. $137 / 81 \mathrm{mmHg}$ ) significantly slowed the progression of diabetic nephropathy and retinopathy and reduced the incidence of stroke (all pre-specified secondary endpoints) [26]. Interestingly, both of these trials included patients with a baseline $\mathrm{BP}<140 /$ $85 \mathrm{mmHg}$, supporting the benefits of BP lowering in patients with a starting BP lower than the current ESH/ESC target $(<140 / 90 \mathrm{mmHg})$. A DBP target of $80-85 \mathrm{mmHg}$ is supported by the results of the HOT study [21] and the United Kingdom Prospective Diabetes Study (UKPDS) [27], and there is evidence for the benefits of lowering SBP to $130 \mathrm{mmHg}$, but not lower [22, 28, 29]. Nonetheless, 


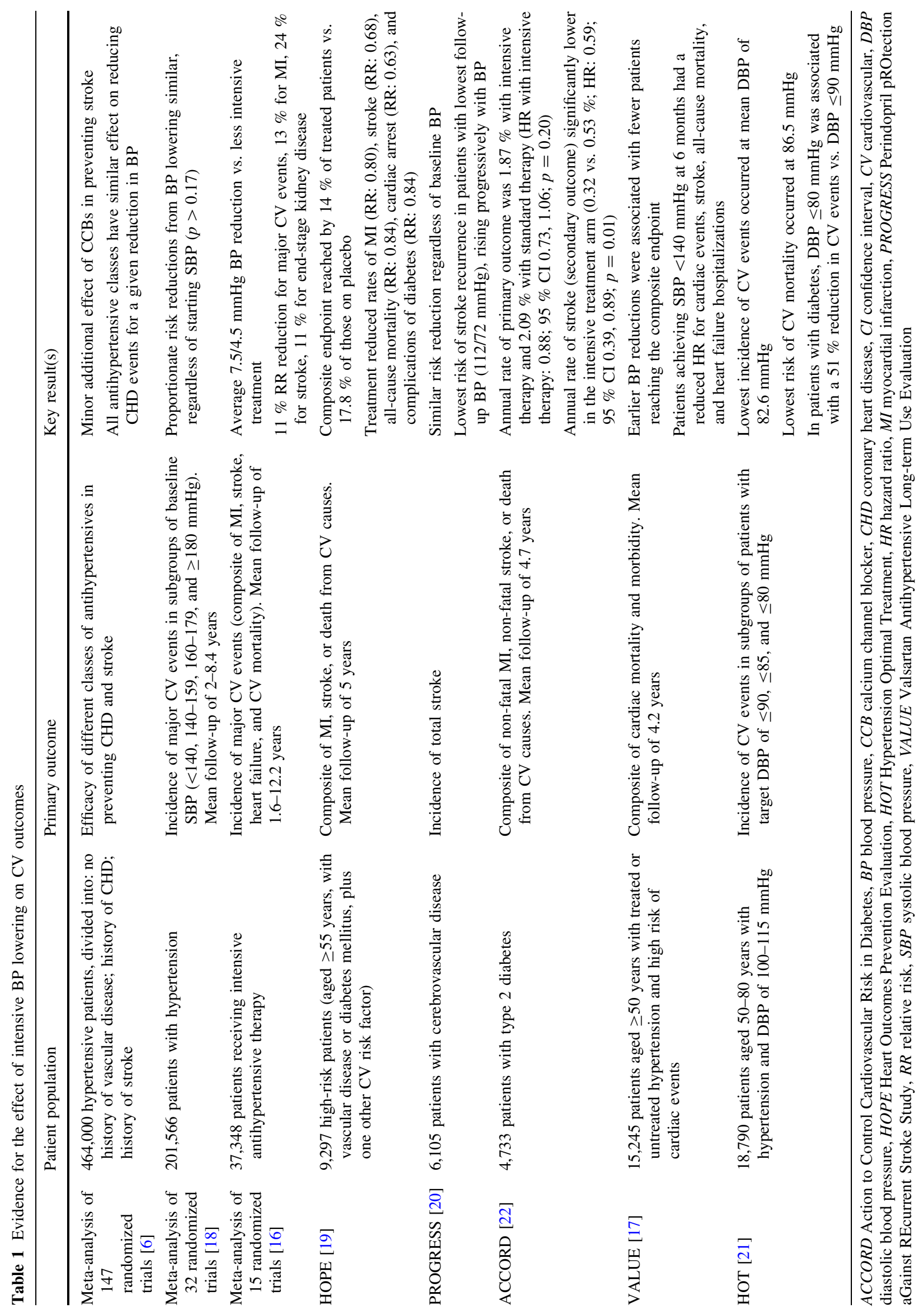


more intensive BP lowering (to $\mathrm{SBP}<130 \mathrm{mmHg}$ ) may reduce organ damage, providing renal and cerebrovascular protection [30]. The benefits of aggressive BP lowering for renal protection are particularly striking for patients with diabetes who have nephropathy; indeed, the Action in Diabetes and Vascular disease: preterAx and diamicroN MR Controlled Evaluation (ADVANCE) study verified that renal events were less frequent in treated patients (mean SBP $134.7 \mathrm{mmHg}$ at follow-up) compared with those given placebo (mean $140.3 \mathrm{mmHg}$ ), with an associated antiproteinuric effect and a reduction in the incidence of new-onset micro- or macro-albuminuria [31]. Patients with diabetes frequently have a number of co-morbidities, meaning that an individualized approach to treatment may be warranted. Hypertensive patients who have experienced previous $\mathrm{CV}$ events have also demonstrated inconsistent outcomes following intensive antihypertensive treatment (to SBP $<130 \mathrm{mmHg}$ ), depending upon the agent used [32-36]. Furthermore, the optimal BP target for protective effects on the kidney, brain, and heart may be divergent [30]. These data support a 'common sense' approach in high-risk individuals, individually tailoring antihypertensive treatment and favoring those agents with proven $\mathrm{CV}$ benefits; however, in clinical practice, the most suitable drug combinations for any given patient are frequently not being prescribed.

A number of RCTs involving elderly patients have shown a reduction in $\mathrm{CV}$ events through $\mathrm{BP}$ lowering, but the mean SBP achieved has not reached $<140 \mathrm{mmHg}$ [12]. Two recent trials of intensive vs. less intensive treatment failed to show a benefit of SBP reduction below $140 \mathrm{mmHg}$ [37, 38], while the Felodipine EVEnt Reduction (FEVER) study sub-analysis showed a reduction in stroke in 3,179 elderly patients by lowering SBP to just below $140 \mathrm{mmHg}$ (vs. $145 \mathrm{mmHg}$ ) [39]. The Cardio-Sis trial involving 1,111 elderly patients (mean age: 67 years) demonstrated that tight BP control (to a mean BP of 132.0/ $77.3 \mathrm{mmHg}$ at 2 years) significantly reduced the incidence of left ventricular hypertrophy and a composite of fatal and non-fatal CV outcomes compared with usual care (which reduced mean $\mathrm{BP}$ to $135.6 / 78.9 \mathrm{mmHg}$ at 2 years) [40]. This benefit of intensive treatment was not associated with an increase in AEs in these patients [40].

Therefore, despite a lack of RCT evidence for aggressive BP targets in high-risk hypertensive patients, which has driven the relaxed BP targets in the $2013 \mathrm{ESH} / \mathrm{ESC}$ guidelines, a number of studies have shown the benefits of more intensive $\mathrm{BP}$ lowering on various $\mathrm{CV}$ outcomes across patient groups. A 'ceiling effect' for treatment benefits has been described for high-risk patients, suggesting that early therapy to address $\mathrm{CV}$ risk before it reaches a high level may increase the benefit of intervention [41]. While we wait for more comprehensive trial evidence on BP targets in high-risk patients with hypertension, a move toward more 'personalized medicine' may be prudent for antihypertensive treatment, selecting BP targets and antihypertensive agents on a per-patient basis according to the patient clinical profile and the proven $\mathrm{CV}$ benefits of each agent.

\section{Monotherapy vs. Combination Therapy}

The previous $2007 \mathrm{ESH} / \mathrm{ESC}$ guidelines stressed that most patients would require more than one antihypertensive drug to achieve their BP target. Conversely, the updated 2013 guidelines present a more balanced discussion of the advantages and disadvantages of initiating hypertensive patients on monotherapy vs. combination therapy. Initiating monotherapy allows clear determination of the drug's efficacy and tolerability, while one of the agents may be ineffective with combination therapy. Monotherapy has a clear place in the treatment algorithm, especially for grade 1 or mild hypertension [42]. However, when monotherapy is insufficient or poorly tolerated, finding an alternative monotherapy that is more effective and/or better tolerated can be difficult and may discourage adherence. Escalating the dosage of a prescribed monotherapy may be less effective for BP reduction than combining agents from different antihypertensive classes [43]. Combination therapy allows a more prompt BP response vs. up titration of monotherapy, has a greater probability of achieving target $\mathrm{BP}$ in patients with a higher BP, and may encourage patient adherence [2]. Compared with monotherapy, combining antihypertensive drugs also lowers the incidence of major $\mathrm{CV}$ events (stroke and ischemic heart disease) [6] and initiating low-dose combination therapy may have greater $\mathrm{CV}$ benefits than starting on monotherapy [44]. Additionally, combination of certain classes of antihypertensive agents has a fully additive effect, allowing earlier, larger, and more sustained reductions in BP than up titration of monotherapy and a sequential add-on regimen [44].

The 2013 ESH/ESC guidelines reconfirm the importance of initiating combination therapy in high-risk patients and those with markedly high baseline BP [2], with initial combination therapy generally recommended for patients with SBP/DBP $>15-20 />10 \mathrm{mmHg}$ above the target [44].

\subsection{Choice of Antihypertensive Agent}

All classes of antihypertensive agent recommended for monotherapy by the different international societies are shown in Table 3 [2-4, 23-25, 45]. Overall, the five main classes of antihypertensive agents (ACE inhibitors, ARBs, $\beta$-blockers, CCBs, and thiazide diuretics) have comparable clinical efficacy as monotherapy [6, 7, 9]. However, 


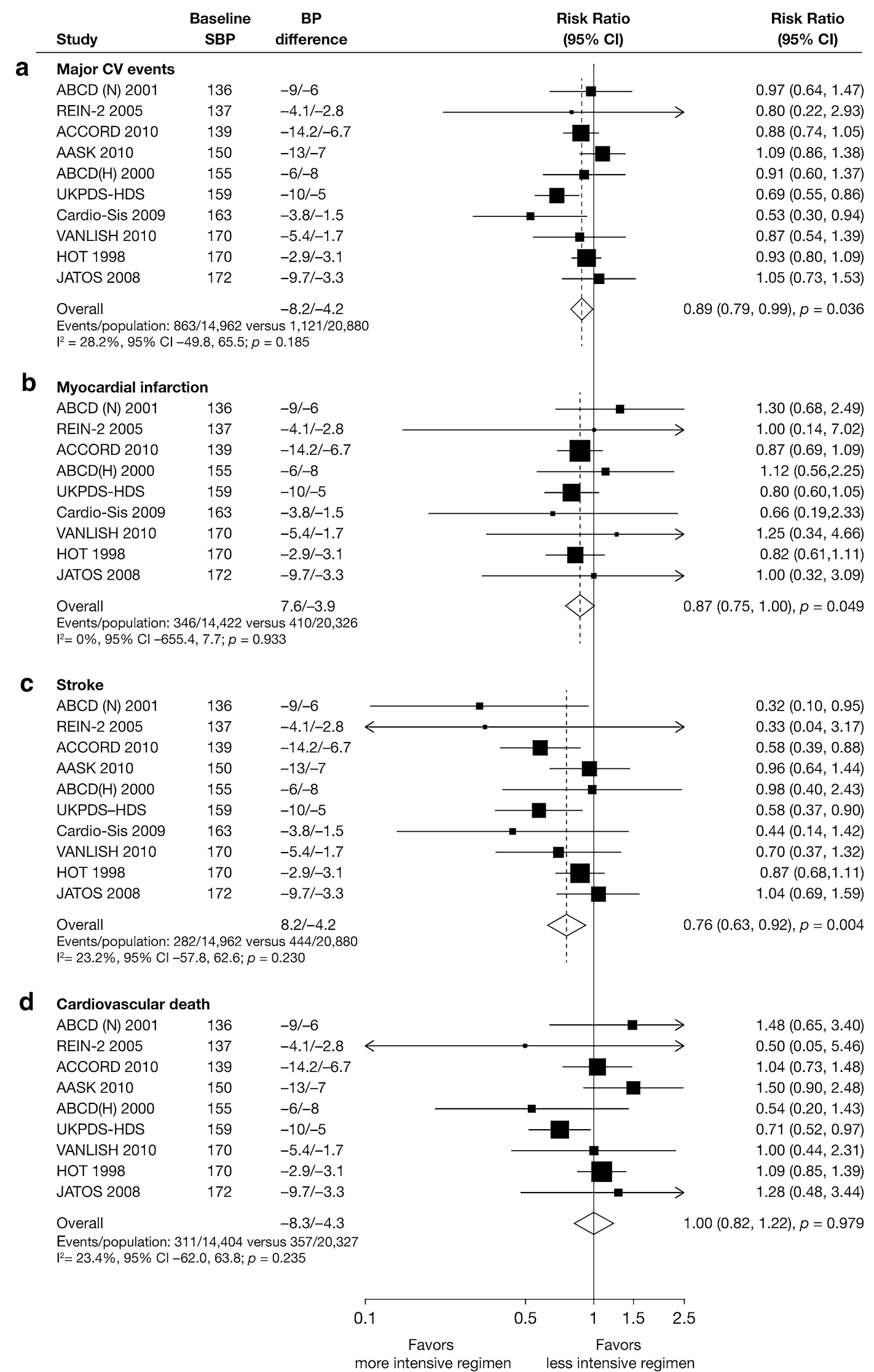


4 Fig. 1 Effect of intensive BP lowering on risk of $\mathrm{CV}$ outcomes: a major CV events, b MI, c stroke, and d CV mortality. AASK African American Study of Kidney Disease and Hypertension, $A B C D$ Appropriate Blood pressure Control in Diabetes, ACCORD Action to Control Cardiovascular Risk in Diabetes, $B P$ blood pressure, $C I$ confidence interval, $C V$ cardiovascular, HOT Hypertension Optimal Treatment, JATOS Japanese trial to assess optimal systolic blood pressure in elderly hypertensive patients, $M I$ myocardial infarction, $R E I N-2$ Ramipril Efficacy in Nephropathy 2, UKPDS-HDS United Kingdom Prospective Diabetes Study-Hypertension in Diabetes Study. Reprinted from [16]

$\beta$-blockers are losing favor as recommended initial therapy for most patients because of questions about their efficacy in preventing stroke and other $\mathrm{CV}$ events, and their adverse effects on glucose metabolism [3, 4]. In contrast, CCBs have been cleared of the suspicion of increasing the incidence of coronary events $[2,5]$ and these agents have been reported to exhibit the lowest inter-individual variation in SBP vs. other antihypertensive classes, which may be linked to a reduced risk of stroke $[6-8,46]$. However, these data require confirmation in future trials.

Optimal choice of initial antihypertensive treatment can establish early benefits of BP control and encourage adherence. Consideration should be given to the potential for up titration of monotherapy and later combination therapy; choosing an efficacious monotherapy that can be continued as part of a preferred combination regimen may be beneficial. For example, the Valsartan Antihypertensive Long-term Use Evaluation (VALUE) study demonstrated that both CCB (amlodipine)-based and ARB (valsartan)based regimens, including stepped up titration of monotherapy $(5-10 \mathrm{mg} /$ day amlodipine; $80-160 \mathrm{mg} /$ day valsartan) followed by combination with a thiazide diuretic, were similar with regard to the primary outcome of composite cardiac mortality and morbidity. The CCB-based regimen gave more pronounced $\mathrm{BP}$ reduction, especially in the early stages of treatment (SBP/DBP in amlodipine group was 4.0/2.1 $\mathrm{mmHg}$ lower than in the valsartan group at 1 month, and $2.1 / 1.6 \mathrm{mmHg}$ lower at 6 months), and was associated with a lower incidence of MI and stroke over the course of the study (mean follow-up 4.2 years) (Fig. 2) [47]. The stepped up titration of monotherapy in VALUE may not have been equipotent with regard to the approved maximal dosing of each agent; however, the results emphasize the importance of prompt BP control in high-risk patients with hypertension.

Some agents may have benefits over others in subgroups of patients [2]; for example, in the Avoiding Cardiovascular events through COMbination therapy in Patients LIving with Systolic Hypertension (ACCOMPLISH) trial, combination of an ACE inhibitor with a CCB provided a $20 \%$ relative risk reduction over an ACE inhibitor-diuretic combination for the primary outcome of composite fatal and non-fatal CV events in elderly patients with hypertension (age $\geq 65$ years) [48]. In patients with existing angina or atrial fibrillation, CCB or $\beta$-blocker therapy may offer additional benefits above BP lowering (a heart-ratelowering $\mathrm{CCB}$ such as verapamil or diltiazem for rapid atrial fibrillation); for patients with MI or heart failure, a $\beta$ blocker, ACE inhibitor, or ARB may be preferred; and for those with peripheral artery disease, an ACE inhibitor or $\mathrm{CCB}$ is recommended [2]. Dihydropyridine CCBs are the only class of antihypertensive agent with no compelling contraindications, although they may not be preferred in patients with peripheral edema or heart conditions (rapid heart rate, low ejection fraction) [2]. Other classes of antihypertensive have compelling contraindications when conditions such as asthma (unselective $\beta$-blockers), pregnancy, hyperkalemia, or bilateral renal artery stenosis (ACE inhibitor/ARB) are present [2]. Prescribers should also consider potential AE profiles when considering antihypertensive treatment, as these can be strong deterrents to patient adherence [49].

CCBs may also be a preferred drug class in many antihypertensive combination strategies (with ACE inhibitors, ARBs, and diuretics) [2]. Combination of nifedipine GITS (gastrointestinal therapeutic system) with either losartan or lisinopril has demonstrated greater BP lowering than with either agent alone [50, 51]; in the mulTicenter study evALuating the Efficacy of Nifedipine GITS-

Table 2 Recommended hypertension treatment targets (SBP/DBP) according to global guideline committees

\begin{tabular}{|c|c|c|c|c|c|c|}
\hline & \multicolumn{6}{|c|}{ Guideline $(\mathrm{mmHg})$} \\
\hline & Europe [2] & Canada [23] & UK [25] & International [4] & USA [3] & China [24] \\
\hline Diabetes mellitus & $<140 /<85$ & $<130 /<80$ & - & $<140 /<90$ & $<140 /<90$ & $<130 /<80$ \\
\hline Elderly (age $\geq 65$ years) & $140-150 /<90^{\mathrm{a}}$ & $<140 /<90$ & $<140 /<90$ & $<140 /<90$ & $<150 /<90^{\mathrm{a}}$ & $<150 /<90^{\mathrm{a}}$ \\
\hline Very elderly (age $\geq 80$ years) & $140-150 /<90$ & $<150 /<90$ & $<150 /<90$ & $<150 /<90$ & - & - \\
\hline CKD & $<140 /<90$ & $<140 /<90$ & - & $<140 /<90$ & $<140 /<90$ & $<130 /<80$ \\
\hline All others & $<140 /<90$ & $<140 /<90$ & $<140 /<90$ & $<140 /<90$ & $<140 /<90$ & $<140 /<90$ \\
\hline
\end{tabular}

- not specified individually, $C K D$ chronic kidney disease, $D B P$ diastolic blood pressure, SBP systolic blood pressure

a $<140 / 90 \mathrm{mmHg}$, if tolerable 
Table 3 Recommendations regarding monotherapy and combination hypertension treatment according to global guideline committees

ESH/ESC (Europe) [2] Diuretics, CCBs, ACE inhibitors, ARBs, and $\beta$-blockers are suitable for the initiation and maintenance of treatment, alone or in combination

Combination therapy should be considered in patients at high risk or with markedly high BP. CCB-ACE inhibitor, CCB-ARB, and CCB-thiazide diuretic are preferred combinations

NICE (UK) [25]

ISH-ASH (international) [4]

International Society on Hypertension in Blacks [45]

Canadian Hypertension Education Program [23]

Joint National Committee (USA) [3]

Chinese Hypertension League [24]
$\mathrm{CCBs}$ are recommended as first line in patients aged $\geq 55$ years and in Blacks of African or Caribbean origin of any age (unless compelling indications against). Other patients aged $<55$ years may be offered an ACE inhibitor or a low-cost ARB

The combination of a CCB-ACE inhibitor or CCB-ARB are recommended as second-line treatment options

An ACE inhibitor or ARB should be initiated as monotherapy in non-Black patients aged $<60$ years and a $\mathrm{CCB}$ or thiazide diuretic in those aged $>60$ years $(\mathrm{CCB}$ or thiazide diuretic recommended for all Black patients)

Dose adjustment or a combination with another class of agent should be considered every $2-3$ weeks if response is not seen. Combination therapy (CCB or thiazide diuretic plus ACE inhibitor or ARB) should be considered first line in patients with $\mathrm{BP} \geq 20 / 10 \mathrm{mmHg}$ above the target

In the absence of compelling indications, when BP is near goal levels, monotherapy with a diuretic or a CCB is preferred because of a greater likelihood of attaining goal BP with either of these agents as monotherapy in Blacks. Combination therapy should be initiated when SBP is $>15 \mathrm{mmHg}$ and/or DBP is $>10 \mathrm{mmHg}$ above goal levels. CCBs or diuretics in combination with each other or with an ACE inhibitor or ARB are recommended

Thiazide diuretics, $\beta$-blockers (in patients aged $<60$ years), ACE inhibitors (in non-Black patients), long-acting CCBs or ARBs are recommended as initial monotherapy. Combination of two first-line drugs may be considered as initial therapy if SBP is $>20 \mathrm{mmHg}$ or DBP $>10 \mathrm{mmHg}$ above the target. Two-drug combinations of $\beta$-blockers, ACE inhibitors, and ARBs are not recommended

Thiazide-type diuretics, CCBs, ACE inhibitors, or ARBs are recommended as initial treatment in nonBlack patients with hypertension and thiazide-type diuretics or CCBs for the general Black population. If goal $\mathrm{BP}$ is not reached within 1 month, up titration or combination with another class of agent should be considered. ACE inhibitors and ARBs are recommended to be included in antihypertensive therapy in patients with CKD, to improve kidney outcomes

Thiazide diuretics, CCBs, ACE inhibitors, ARBs, and $\beta$-blockers can be used for initial or maintenance therapy, alone or in combination

$A C E$ angiotensin-converting enzyme, $A R B$ angiotensin II receptor blocker, $B P$ blood pressure, $C C B$ calcium channel blocker, $C K D$ chronic kidney disease, DBP diastolic blood pressure, ESC European Society of Cardiology, ESH European Society of Hypertension, ISH-ASH International Society of Hypertension/American Society of Hypertension, NICE National Institute for Health and Clinical Excellence, SBP systolic blood pressure

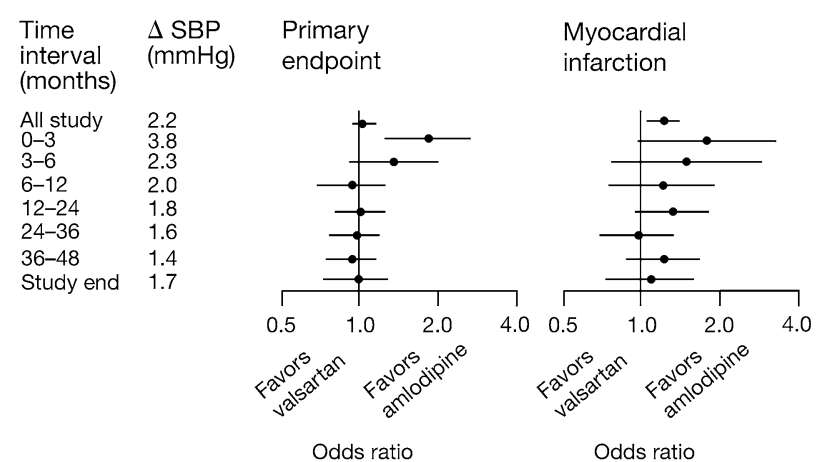

Fig. 2 OR for major CV events for antihypertensive treatment with ARB-based therapy (valsartan) vs. CCB-based therapy (amlodipine). $A R B$ angiotensin II receptor blocker, $C C B$ calcium channel blocker, $C V$ cardiovascular, $O R$ odds ratio, $S B P$ systolic blood pressure $\triangle \mathrm{SBP}$
Heart-failure Stroke All-cause death hospitalizations

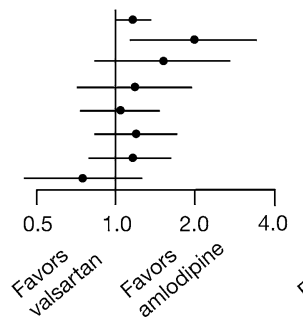

Odds ratio

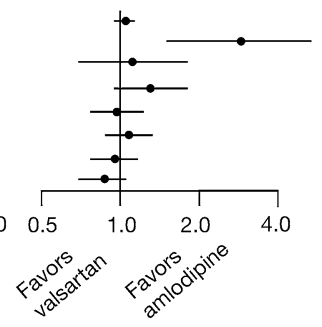

Odds ratio
Odds ratio

represents the difference in SBP between the treatment groups (amlodipine-valsartan). Primary endpoint consisted of a composite of cardiac morbidity and mortality. Reprinted from [47], Copyright (2013), with permission from Elsevier

monotherapy [52]. The Avoiding Cardiovascular events through Combination therapy in Patients Living with Systolic Hypertension (ACCOMPLISH) study was the only 
large trial to directly compare RAS blockade in combination with either a CCB or a diuretic, and demonstrated the benefit of an amlodipine-benazepril combination over a hydrochlorothiazide (HCTZ)-benazepril combination for reducing $\mathrm{CV}$ events in high-risk patients with hypertension [48]. However, the combination of RAS blockade with a diuretic has shown beneficial outcomes in particular subgroups of patients, such as those with congestive heart failure [53], and an ACE inhibitor/diuretic combination appears to demonstrate a particular additive efficacy in Black patients [54]. In the Losartan Intervention For Endpoint reduction in hypertension (LIFE) study, an ARB/ diuretic combination (losartan/HCTZ) showed significantly better reductions in CV morbidity and mortality for similar BP reduction, largely attributable to superior stroke prevention [55]. The Anglo-Scandinavian Cardiac Outcomes Trial (ASCOT) showed lower visit-to-visit BP variability with a CCB-ACE inhibitor combination (amlodipine based) vs. a $\beta$-blocker-diuretic combination (atenolol based), and the CCB-ACE inhibitor combination was associated with a $34 \%$ reduction in new-onset diabetes [56]. Dual RAS blockade is no longer recommended owing to concerns regarding renal damage and an increased incidence of stroke [57, 58].

International guidelines vary in their recommendations toward initiating monotherapy vs. combination therapy (Table 3). However, these guidelines provide some consistent recommendations on the choice of agent; for example, CCB use in both monotherapy and combination therapy is highlighted favorably in the European (ESH/ ESC), the United Kingdom (National Institute for Health and Clinical Excellence), American (Joint National Committee on Prevention, Detection, Evaluation, and Treatment of High Blood Pressure), and Canadian (Canadian Hypertension Education Program) guidelines, as well as the International Society of Hypertension/American Society of Hypertension and the Chinese Hypertension League guidelines [2-4, 23-25]. The use of ACE inhibitors and ARBs is also recommended.

Therefore, each patient's individual demographics, BP level, CV risk, co-morbidities, and preference (including any previously reported side effects), as well as the evidence for preferential antihypertensive agent benefits, should be considered when deciding upon the optimal regimen and type of antihypertensive treatment. CCBs appear to be a favorable choice of antihypertensive agent for monotherapy and in combination with other agent classes, and may provide benefits over other classes for certain patient groups and CV outcomes. Further research is needed into specific beyond BP-lowering class effects, but $\mathrm{CCBs}$ are an established group of antihypertensive agents that looks to play a sustained role in future hypertension treatment strategies.

\section{Diagnosis and Monitoring of Hypertension}

The importance of ABPM and HBPM for the diagnosis and monitoring of hypertension has been known for some time, and newer guidelines, including the 2013 ESH/ESC recommendations, are recognizing this and providing diagnostic thresholds $[2,25]$. An official position paper on ABPM has also recently been published [59]. Office BP is usually higher than ABPM and HBPM; a large study of $\mathrm{ABPM}$ vs. clinic BP measurements found that the latter were on average $6 / 3 \mathrm{mmHg}$ higher than the daytime ambulatory BP and 10/5 mmHg higher than 24-h ABPM values [60]. These data have important consequences for accurate diagnosis and selection of optimal treatment strategies. This difference in BP according to the measurement technique used is reflected in the current ESH/ ESC recommended definitions of hypertension using each method (Table 4).

The most commonly used ABPM parameters are mean daytime, mean night-time, mean 24-h BP, and BP load. BP load is defined as the percentage of readings in a given time period (day, night, $24 \mathrm{~h}$ ) that exceed a pre-defined threshold BP (typically the 'normal' BP for that period). However, differences in BP load can be largely explained by differences in BP variability and no information on the extent to which the threshold has been exceeded is provided, which is of prognostic importance. The consistency of antihypertensive treatment over a 24 -h period is reflected by the trough:peak ratio and smoothness index, derived from 24-h ABPM data. Trough:peak ratios are highly variable within any individual and are thus not a reliable clinical measure. Conversely, the smoothness index reflects the size of BP reduction with treatment and homogeneity throughout the 24-h period (higher values signifying antihypertensive treatments with a large and consistent effect). A higher smoothness index (lower BP variability) is associated with improved $\mathrm{CV}$ outcomes and reduced organ damage [61]. Classification of daytime and night-time periods may be best done using information from patient diaries on their sleep patterns; however, fixed time periods

Table 4 ESH/ESC definitions of hypertension using office and outof-office BP measurements

Office BP measurement $\quad \mathrm{SBP} \geq 140 \mathrm{mmHg}$ and/or DBP $\geq 90 \mathrm{mmHg}$ Ambulatory BP measurements

\begin{tabular}{ll} 
Daytime (awake) & $\mathrm{SBP} \geq 135 \mathrm{mmHg}$ and/or $\mathrm{DBP} \geq 85 \mathrm{mmHg}$ \\
Night-time (asleep) & $\mathrm{SBP} \geq 120 \mathrm{mmHg}$ and/or $\mathrm{DBP} \geq 70 \mathrm{mmHg}$ \\
24-h & $\mathrm{SBP} \geq 130 \mathrm{mmHg}$ and/or $\mathrm{DBP} \geq 80 \mathrm{mmHg}$ \\
Home BP measurement & $\mathrm{SBP} \geq 135 \mathrm{mmHg}$ and/or $\mathrm{DBP} \geq 85 \mathrm{mmHg}$ \\
\hline
\end{tabular}

$B P$ blood pressure, DBP diastolic blood pressure, ESC European Society of Cardiology, ESH European Society of Hypertension, $S B P$ systolic blood pressure 
representing day (09:00-21:00) and night (01:00-06:00) are common, eliminating much of the inter- and intrapatient variability, but sacrificing early-phase night sleep BP dipping and early morning surge information, which have significance for CV outcomes. Different BP sampling intervals can be employed; however, it is recommended not to exceed $30 \mathrm{~min}$ between readings, to avoid incorrect estimation of mean values [59]. It is recommended to repeat ABPM measurement if $<70 \%$ of the expected measurements within $24 \mathrm{~h}$ are recorded, including 20 valid awake and seven valid sleep measurements [59]. ABPM readings are usually performed on the non-dominant arm (to reduce disruption to everyday activities), but there is currently a lack of consensus regarding the most suitable arm position for the patient to adopt during measurements, with implications for data accuracy [62].

ABPM and HBPM may have greater prognostic value for risk of CV events than office measurements [2, 63, 64] and $\mathrm{ABPM}$ is associated with a doubling of BP control rates vs. office measurements [65]. Central BP measurement has also been noted as an independent predictor of $\mathrm{CV}$ events in various populations; however, its relative value vs. brachial measurements is still under debate [2] and the benefit of achieving central BP reduction through antihypertensive treatment for patient outcomes has been investigated [Nifedipine GITS's Effect on Central Pressure Assessed by Applanation Tonometry (FOCUS) study, NCT01071122].

Therapeutic decisions based on ABPM are superior to those based on office measurements [66]; for instance, the Valsartan in Systolic Hypertension (Val-Syst) trial demonstrated that the treatment-induced reduction in clinic SBP was considerably greater than the mean 24-h BP reduction, measured by ABPM (31.9 vs. $13.4 \mathrm{mmHg}$, respectively), which was attributable to a white coat effect [67]. Furthermore, in patients with white coat hypertension, no change was seen in 24-h BP or that in the hour following treatment, whereas a large decrease in SBP was seen [67]. Had ABPM not been used, this apparent BP-lowering effect would have been wrongly attributed to treatment. Indeed, ABPM has been shown to be the most cost-effective strategy for diagnosing hypertension in patients of all ages, with the additional costs of initial diagnosis offset by savings from targeted treatment $[68,69]$.

HBPM offers more extensive data than office BP measurement can provide, is less expensive, is widely available and convenient, and has been shown to improve patient compliance with treatment and BP control [68]. In a study of 80 patients, HBPM was demonstrated to lead to fewer erroneous diagnoses compared with office BP measurement (3.8\% vs. $15 \%$, respectively), and was more effective for monitoring the effect of therapy in mild or moderate hypertension [70]. BP variability measured by
HBPM was also not significantly different to that derived from ABPM [70]. However, unlike ABPM, HBPM does not include BP during sleep or work and cannot capture short-term variability; therefore, HBPM should be considered complementary to ABPM [71]. Once concordance between HBPM and ABPM can be established, HBPM may be appropriate for long-term monitoring [68]. A new study [Targets and self-management for the control of BP in stroke and at-risk groups (TAMSIN-SR)] will assess the value of HBPM for self-management of hypertension in high-risk patients [72].

ABPM and HBPM are vital for the diagnosis of patients with non-sustained hypertension, who may still be at risk of adverse CV events [73]. White coat hypertension is associated with a lower risk of organ damage and CV events than sustained hypertension, and patients with raised $\mathrm{BP}$ on ABPM or HBPM show increased risk of $\mathrm{CV}$ and all-cause mortality [73]. Moreover, patients with white coat hypertension may respond differently to antihypertensive agents, and develop more AEs, compared with patients who have sustained hypertension [66]. Masked hypertension is prevalent in those with chronic kidney disease, diabetes, and obstructive sleep apnea [74]. These patients may only have high normal office BP, but demonstrate a greater risk for organ damage and CV events than patients with white coat hypertension [2]. However, many patients with non-sustained (or masked) hypertension remain undiagnosed, presenting a hidden risk for future CV events. Waiting to treat hypertension increases total risk, and progression to high risk is often not entirely reversible [41]. Therefore, diagnosing and treating non-sustained hypertension is likely to be beneficial in the longer term. Nonetheless, classification of patients based solely on differences between in- and outof-office BP measurements may be misleading, as it may not consider the significance of BP during sleep [75].

Many international guidelines are now in agreement that ABPM should be used for the exclusion or confirmation of white coat hypertension, with a move towards its use to diagnose hypotension and resistant hypertension, to monitor therapy efficacy over a $24-\mathrm{h}$ period, as well as for assessing nocturnal BP dipping (difference between daytime and night-time BP) [59]. Indeed, there is compelling evidence that data on nocturnal BP levels may be superior to office BP measurements in predicting patient outcome [59], supporting greater use of ABPM generally. White coat hypertension, nocturnal dipping, nocturnal hypertension, and increased BP variability are more common in high-risk patients than in low-risk patients with high BP; these conditions are best characterized using ABPM, allowing improved management of patients already at increased risk of CV events [59].

Overall, the value of ABPM and HBPM for the diagnosis and monitoring of hypertension needs to be more 
widely understood and utilized, and clear strategies and BP targets established for these methods.

\section{Conclusions}

The 2013 ESH/ESC hypertension management guidelines recommend a more unified $\mathrm{BP}$ target for most patients, owing to a lack of compelling RCT evidence for the previously more aggressive BP targets in high-risk patients. However, substantial evidence suggests that further $\mathrm{CV}$ benefits are available from more intensive BP lowering and, until more solid RCT data are available, individualized treatment of high-risk patients may be prudent. Individual patient demographics, BP level, CV risk, comorbidities, and preference should influence the chosen treatment strategy. An optimal therapy regimen that lowers $\mathrm{BP}$ and $\mathrm{CV}$ risk while being tolerable will encourage patient adherence. CCBs appear to be a favorable choice for monotherapy and in combination (with other antihypertensive agent classes) in many patients, and may provide specific beyond-BP-lowering benefits. The importance of ABPM and HBPM for comprehensive diagnosis of hypertensive conditions, patient risk stratification, and appropriate treatment selection should be more widely acknowledged and utilized. These methods are likely to play an increasing role in the hypertension field.

Acknowledgments Writing support in the preparation of this manuscript was provided by PAREXEL International, and this support was funded by Bayer HealthCare.

All authors contributed to the concept of the manuscript, critically reviewed the draft, and approved the final version.

Conflict of interest Sverre Kjeldsen has received grant funding from AstraZeneca and Pronova; honorarium and consultancy fees from Bayer HealthCare, Serodūs Pharmaceuticals, Takeda, and Medtronic; lectureship fees from AstraZeneca, Bayer HealthCare, Medtronic, Merck Sharp \& Dohme, Novartis, and Takeda; and royalties from Gyldendal. Tonje Aksnes has received lecture honorarium and travel support from AstraZeneca, Merck Sharp \& Dohme, Novartis, and Pfizer. Luis Ruilope has received honorarium and consultancy fees from Bayer HealthCare.

Open Access This article is distributed under the terms of the Creative Commons Attribution Noncommercial License which permits any noncommercial use, distribution, and reproduction in any medium, provided the original author(s) and the source are credited.

\section{References}

1. Mancia G, De BG, Dominiczak A, Cifkova R, Fagard R, Germano G, et al. 2007 ESH-ESC practice guidelines for the management of arterial hypertension: ESH-ESC Task Force on the Management of Arterial Hypertension. J Hypertens. 2007;25: $1751-62$.
2. Mancia G, Fagard R, Narkiewicz K, Redon J, Zanchetti A, Bohm M, et al. $2013 \mathrm{ESH} / \mathrm{ESC}$ guidelines for the management of arterial hypertension: the Task Force for the Management of Arterial Hypertension of the European Society of Hypertension (ESH) and of the European Society of Cardiology (ESC). Eur Heart J. 2013;34:2159-219.

3. James PA, Oparil S, Carter BL, Cushman WC, Dennison-Himmelfarb C, Handler J, et al. Evidence-based guideline for the management of high blood pressure in adults: report from the panel members appointed to the Eighth Joint National Committee (JNC 8). JAMA. 2014;311:507-20.

4. Weber MA, Schiffrin EL, White WB, Mann S, Lindholm LH, Kenerson JG, et al. Clinical practice guidelines for the management of hypertension in the community: a statement by the American Society of Hypertension and the International Society of Hypertension. J Hypertension. 2014;32:3-15.

5. Effects of calcium antagonists on the risks of coronary heart disease, cancer and bleeding. Ad Hoc Subcommittee of the Liaison Committee of the World Health Organisation and the International Society of Hypertension. J Hum Hypertens. 1997;11:331-2.

6. Law MR, Morris JK, Wald NJ. Use of blood pressure lowering drugs in the prevention of cardiovascular disease: meta-analysis of 147 randomised trials in the context of expectations from prospective epidemiological studies. BMJ. 2009;338:b1665.

7. Turnbull F, Neal B, Algert C, Chalmers J, Chapman N, Cutler J, et al. Effects of different blood pressure-lowering regimens on major cardiovascular events in individuals with and without diabetes mellitus: results of prospectively designed overviews of randomized trials. Arch Intern Med. 2005;165:1410-9.

8. Verdecchia P, Reboldi G, Angeli F, Gattobigio R, Bentivoglio M, Thijs L, et al. Angiotensin-converting enzyme inhibitors and calcium channel blockers for coronary heart disease and stroke prevention. Hypertension. 2005;46:386-92.

9. Turnbull F. Effects of different blood-pressure-lowering regimens on major cardiovascular events: results of prospectively-designed overviews of randomised trials. Lancet. 2003;362:1527-35.

10. Arima H, Murakami Y, Lam TH, Kim HC, Ueshima H, Woo J, et al. Effects of pre hypertension and hypertension subtype on cardiovascular disease in the Asia-Pacific region. Hypertension. 2012;59:1118-23.

11. He FJ, MacGregor GA. Cost of poor blood pressure control in the UK: 62000 unnecessary deaths per year. J Hum Hypertens. $2003 ; 17: 455-7$.

12. Zanchetti A, Grassi G, Mancia G. When should antihypertensive drug treatment be initiated and to what levels should systolic blood pressure be lowered? A critical reappraisal. J Hypertens. 2009;27:923-34.

13. Hypertension Detection and Follow-up Program Cooperative Group. The effect of treatment on mortality in "mild" hypertension: results of the hypertension detection and follow-up program. N Engl J Med. 1982;307:976-80.

14. Liu L, Zhang Y, Liu G, Li W, Zhang X, Zanchetti A. The Felodipine Event Reduction (FEVER) Study: a randomized longterm placebo-controlled trial in Chinese hypertensive patients. J Hypertens. 2005;23:2157-72.

15. Medical Research Council Working Party. MRC trial of treatment of mild hypertension: principal results. Br Med J (Clin Res Ed). 1985;291:97-104.

16. Lv J, Neal B, Ehteshami P, Ninomiya T, Woodward M, Rodgers A, et al. Effects of intensive blood pressure lowering on cardiovascular and renal outcomes: a systematic review and metaanalysis. PLoS Med. 2012;9:e1001293.

17. Weber MA, Julius S, Kjeldsen SE, Brunner HR, Ekman S, Hansson L, et al. Blood pressure dependent and independent effects of antihypertensive treatment on clinical events in the VALUE trial. Lancet. 2004;363:2049-51. 
18. Czernichow S, Zanchetti A, Turnbull F, Barzi F, Ninomiya T, Kengne AP, et al. The effects of blood pressure reduction and of different blood pressure-lowering regimens on major cardiovascular events according to baseline blood pressure: meta-analysis of randomized trials. J Hypertens. 2011;29:4-16.

19. The Heart Outcomes Prevention Evaluation Study Investigators. Effects of an angiotensin-converting-enzyme inhibitor, ramipril, on cardiovascular events in high-risk patients. N Engl J Med. 2000;342:145-53.

20. Arima H, Chalmers J, Woodward M, Anderson C, Rodgers A, Davis $\mathrm{S}$, et al. Lower target blood pressures are safe and effective for the prevention of recurrent stroke: the PROGRESS trial. J Hypertens. 2006;24:1201-8.

21. Hansson L, Zanchetti A, Carruthers SG, Dahlof B, Elmfeldt D, Julius S, et al. Effects of intensive blood-pressure lowering and low-dose aspirin in patients with hypertension: principal results of the Hypertension Optimal Treatment (HOT) randomised trial: HOT Study Group. Lancet. 1998;351:1755-62.

22. Cushman WC, Evans GW, Byington RP, Goff DC Jr, Grimm RH Jr, Cutler JA, et al. Effects of intensive blood-pressure control in type 2 diabetes mellitus. N Engl J Med. 2010;362:1575-85.

23. Hypertension Canada. Canadian Hypertension Education Program (CHEP) 2013 recommendations. Hypertension Canada. http://www.hypertension.ca/chep. Accessed 9 Aug 2013.

24. Liu LS. 2010 Chinese guidelines for the management of hypertension. Zhonghua Xin Xue Guan Bing Za Zhi. 2011;39:579-615.

25. National Institute for Health and Care Excellence. Hypertension: clinical management of primary hypertension in adults (CG127). NICE UK. http://publications.nice.org.uk/hypertension-cg127. Accessed 9 Aug 2013.

26. Schrier RW, Estacio RO, Esler A, Mehler P. Effects of aggressive blood pressure control in normotensive type 2 diabetic patients on albuminuria, retinopathy and strokes. Kidney Int. 2002;61: 1086-97.

27. Tight blood pressure control and risk of macro vascular and microvascular complications in type 2 diabetes: UKPDS 38. UK Prospective Diabetes Study Group. BMJ. 1998;317:703-3.

28. Cederholm J, Gudbjörnsdottir S, Eliasson B, Zethelius B, EegOlofsson K, Nilsson PM, et al. Blood pressure and risk of cardiovascular diseases in type 2 diabetes: further findings from the Swedish National Diabetes Register (NDR-BP II). J Hypertens. 2012;30:2020-30.

29. Redon J, Mancia G, Sleight P, Schumacher H, Gao P, Pogue J, et al. Safety and efficacy of low blood pressures among patients with diabetes: subgroup analyses from the ONTARGET (ONgoing Telmisartan Alone and in combination with Ramipril Global Endpoint Trial). J Am Coll Cardiol. 2012;59:74-83.

30. Mancia G, Grassi G, Zanchetti A. Antihypertensive treatment and blood pressure in diabetic and nondiabetic patients: the lower, the better? Diabetes Care. 2011;34(Suppl 2):S304-7.

31. de Galan BE, Perkovic V, Ninomiya T, Pillai A, Patel A, Cass A, et al. Lowering blood pressure reduces renal events in type 2 diabetes. J Am Soc Nephrol. 2009;20:883-92.

32. Fox KM. Efficacy of perindopril in reduction of cardiovascular events among patients with stable coronary artery disease: randomised, double-blind, placebo-controlled, multicentre trial (the EUROPA study). Lancet. 2003;362:782-8.

33. Mancia G, Laurent S, Agabiti-Rosei E, Ambrosioni E, Burnier M, Caulfield MJ, et al. Reappraisal of European guidelines on hypertension management: a European Society of Hypertension Task Force document. J Hypertens. 2009;27:2121-58.

34. Nissen SE, Tuzcu EM, Libby P, Thompson PD, Ghali M, Garza $D$, et al. Effect of antihypertensive agents on cardiovascular events in patients with coronary disease and normal blood pressure: the CAMELOT study: a randomized controlled trial. JAMA. 2004;292:2217-25.
35. Pitt B, Byington RP, Furberg CD, Hunninghake DB, Mancini $\mathrm{GB}$, Miller ME, et al. Effect of amlodipine on the progression of atherosclerosis and the occurrence of clinical events: PREVENT Investigators. Circulation. 2000;102:1503-10.

36. Poole-Wilson PA, Lubsen J, Kirwan BA, van Dalen FJ, Wagener $\mathrm{G}$, Danchin N, et al. Effect of long-acting nifedipine on mortality and cardiovascular morbidity in patients with stable angina requiring treatment (ACTION trial): randomised controlled trial. Lancet. 2004;364:849-57.

37. JATOS Study Group. Principal results of the Japanese trial to assess optimal systolic blood pressure in elderly hypertensive patients (JATOS). Hypertens Res. 2008;31:2115-27.

38. Ogihara T, Saruta T, Rakugi H, Matsuoka H, Shimamoto K, Shimada K, et al. Target blood pressure for treatment of isolated systolic hypertension in the elderly: valsartan in elderly isolated systolic hypertension study. Hypertension. 2010;56:196-202.

39. Zhang $\mathrm{Y}$, Zhang $\mathrm{X}$, Liu L, Zanchetti A. Is a systolic blood pressure target $<140 \mathrm{mmHg}$ indicated in all hypertensives? Subgroup analyses of findings from the randomized FEVER trial. Eur Heart J. 2011;32:1500-8.

40. Verdecchia P, Staessen JA, Angeli F, de SG, Achilli A, Ganau A, et al. Usual versus tight control of systolic blood pressure in nondiabetic patients with hypertension (Cardio-Sis): an open-label randomised trial. Lancet. 2009;374:525-3.

41. Zanchetti A. Bottom blood pressure or bottom cardiovascular risk? How far can cardiovascular risk be reduced? J Hypertens. 2009;27:1509-20.

42. Bryce A, Coca A. Treatment of hypertension: monotherapy or combination therapy. Rev Argent Cardiol. 2011;79:355-63.

43. Wald DS, Law M, Morris JK, Bestwick JP, Wald NJ. Combination therapy versus monotherapy in reducing blood pressure: meta-analysis on 11,000 participants from 42 trials. Am J Med. 2009;122:290-300.

44. Kjeldsen SE, Messerli FH, Chiang CE, Meredith PA, Liu L. Are fixed-dose combination antihypertensives suitable as first-line therapy? Curr Med Res Opin. 2012;28:1685-97.

45. Flack JM, Sica DA, Bakris G, Brown AL, Ferdinand KC, Grimm $\mathrm{RH} \mathrm{Jr}$, et al. Management of high blood pressure in Blacks: an update of the International Society on Hypertension in Blacks consensus statement. Hypertension. 2010;56:780-800.

46. Webb AJ, Fischer U, Mehta Z, Rothwell PM. Effects of antihypertensive-drug class on interindividual variation in blood pressure and risk of stroke: a systematic review and meta-analysis. Lancet. 2010;375:906-15.

47. Julius S, Kjeldsen SE, Weber M, Brunner HR, Ekman S, Hansson $\mathrm{L}$, et al. Outcomes in hypertensive patients at high cardiovascular risk treated with regimens based on valsartan or amlodipine: the VALUE randomised trial. Lancet. 2004;363:2022-31.

48. Jamerson K, Weber MA, Bakris GL, Dahlof B, Pitt B, Shi V, et al. Benazepril plus amlodipine or hydrochlorothiazide for hypertension in high-risk patients. N Engl J Med. 2008;359:2417-28.

49. AlGhurair SA, Hughes CA, Simpson SH, Guirguis LM. A systematic review of patient self-reported barriers of adherence to antihypertensive medications using the World Health Organization multidimensional adherence model. J Clin Hypertens (Greenwich). 2012;14:877-86.

50. Kuschnir E, Bendersky M, Resk J, Panart MS, Guzman L, Plotquin $\mathrm{Y}$, et al. Effects of the combination of low-dose nifedipine GITS $20 \mathrm{mg}$ and losartan $50 \mathrm{mg}$ in patients with mild to moderate hypertension. J Cardiovasc Pharmacol. 2004;43:300-5.

51. Taddei S, Omboni S, Ghiadoni L, Caiazza A, Fogari R, Innocenti $\mathrm{P}$, et al. Combination of lisinopril and nifedipine GITS increases blood pressure control compared with single drugs in essential hypertensive patients. J Cardiovasc Pharmacol. 2003;41:579-85.

52. Mancia G, Parati G, Bilo G, Choi J, Kilama MO, Ruilope LM. Blood pressure control by the nifedipine GITS-telmisartan 
combination in patients at high cardiovascular risk: the TALENT study. J Hypertens. 2011;29:600-9.

53. Hunt SA, Baker DW, Chin MH, Cinquegrani MP, Feldman AM, Francis GS, et al. ACC/AHA guidelines for the evaluation and management of chronic heart failure in the adult: executive summary. A report of the American College of Cardiology/ American Heart Association Task Force on practice guidelines (Committee to Revise the 1995 Guidelines for the Evaluation and Management of Heart Failure): developed in collaboration with the International Society for Heart and Lung Transplantation; endorsed by the Heart Failure Society of America. Circulation. 2001;104:2996-3007.

54. Skolnik NS, Beck JD, Clark M. Combination antihypertensive drugs: recommendations for use. Am Fam Physician. 2000;61: 3049-56.

55. Dahlof B, Devereux RB, Kjeldsen SE, Julius S, Beevers G, de FU, et al. Cardiovascular morbidity and mortality in the Losartan Intervention For Endpoint reduction in hypertension study (LIFE): a randomised trial against atenolol. Lancet. 2002;359: 995-1003.

56. Rothwell PM, Howard SC, Dolan E, O'Brien E, Dobson JE, Dahlof B, et al. Effects of beta blockers and calcium-channel blockers on within-individual variability in blood pressure and risk of stroke. Lancet Neurol. 2010;9:469-80.

57. Mann JF, Schmieder RE, McQueen M, Dyal L, Schumacher H, Pogue J, et al. Renal outcomes with telmisartan, ramipril, or both, in people at high vascular risk (the ONTARGET study): a multicentre, randomised, double-blind, controlled trial. Lancet. 2008;372:547-53.

58. Parving HH, Brenner BM, McMurray JJV, de Zeeuw D, Haffner SM, Solomon SD, et al. Cardiorenal end points in a trial of aliskiren for type 2 diabetes. N Engl J Med. 2012;367:2204-13.

59. O'Brien E, Parati G, Stergiou G, Asmar R, Beilin L, Bilo G, et al. European Society of Hypertension position paper on abulatory blood pressure monitoring. J Hypertens. 2013;31:1731-68.

60. Head GA, Mihailidou AS, Duggan KA, Beilin LJ, Berry N, Brown MA, et al. Definition of ambulatory blood pressure targets for diagnosis and treatment of hypertension in relation to clinic blood pressure: prospective cohort study. BMJ. 2010;340:c1104.

61. Parati G, Schumacher H. Blood pressure variability over $24 \mathrm{~h}$ : prognostic implications and treatment perspectives. An assessment using the smoothness index with telmisartan-amlodipine monotherapy and combination. Hypertens Res. 2014;37:187-93.

62. Byrd JB, Brook RD. Arm position during ambulatory blood pressure monitoring: a review of the evidence and clinical guidelines. J Clin Hypertens (Greenwich). 2014;16:225-30.

63. Conen D, Bamberg F. Noninvasive 24-h ambulatory blood pressure and cardiovascular disease: a systematic review and meta-analysis. J Hypertens. 2008;26:1290-9.
64. Ward AM, Takahashi O, Stevens R, Heneghan C. Home measurement of blood pressure and cardiovascular disease: systematic review and meta-analysis of prospective studies. J Hypertens. 2012;30:449-56.

65. Segura J, Banegas JR, Ruilope LM. Usefulness of ambulatory blood pressure monitoring (ABPM) in daily clinical practice: data from the Spanish ABPM registry. Clin Exp Pharmacol Physiol. 2014;41:30-6.

66. O'Brian E. The value of 24-h blood pressure monitoring to assess the efficacy of antihypertensive drug treatment. Hot Top Hypertens. 2011;4:7-23.

67. Palatini P, Dorigatti F, Mugellini A, Spagnuolo V, Vari N, Ferrara R, et al. Ambulatory versus clinic blood pressure for the assessment of anti hypertensive efficacy in clinical trials: insights from the Val-Syst Study. Clin Ther. 2004;26:1436-45.

68. Grossman E. Ambulatory blood pressure monitoring in the diagnosis and management of hypertension. Diabetes Care. 2013;36:S307-11.

69. Lovibond K, Jowett S, Barton P, Caulfield M, Heneghan C, Hobbs FD, et al. Cost-effectiveness of options for the diagnosis of high blood pressure in primary care: a modelling study. Lancet. 2011;378:1219-30.

70. Radchenko G, Sirenko Y, Polischuk S. Home self measurement monitoring of blood pressure: relation to office and ambulatory blood pressure measurement. J Hypertens. 2010;28:14-15.

71. Palatini P. Ambulatory and home blood pressure measurement: complementary rather than competitive methods. Hypertension. 2012;59:2-4.

72. O'Brien C, Bray EP, Bryan S, Greenfield SM, Haque MS, Hobbs $\mathrm{FD}$, et al. Targets and self-management for the control of blood pressure in stroke and at risk groups (TASMIN-SR): protocol for a randomised controlled trial. BMC Cardiovasc Disord. 2013; 13:21.

73. Mancia G, Bombelli M, Brambilla G, Facchetti R, Sega R, Toso $\mathrm{E}$, et al. Long-term prognostic value of white coat hypertension: an insight from diagnostic use of both ambulatory and home blood pressure measurements. Hypertension. 2013;62:168-74.

74. Phillips RA. Controversies in blood pressure goal guidelines and masked hypertension. Ann N Y Acad Sci. 2012;1254:115-22.

75. International Society for Chronobiology, American Association of Medical Chronobiology and Chronotherapeutics, Spanish Society of Applied Chronobiology CaVR, Spanish Society of Atherosclerosis, Romanian Society of Internal Medicine, Hermida RC, et al. Ambulatory blood pressure monitoring recommendations for the diagnosis of adult hypertension, assessment of cardiovascular and other hypertension-associated risk, and attainment of therapeutic goals. Chronobiol Int. 2013;30:355410. 